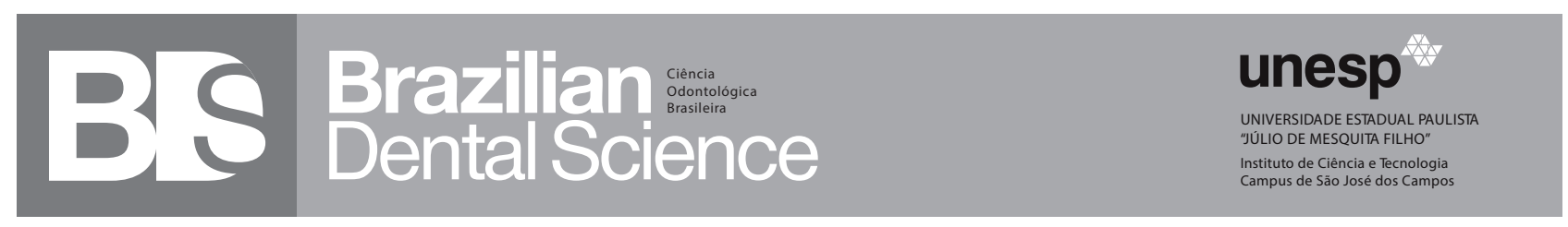

\section{PANDEMIA AND SCIENCE}

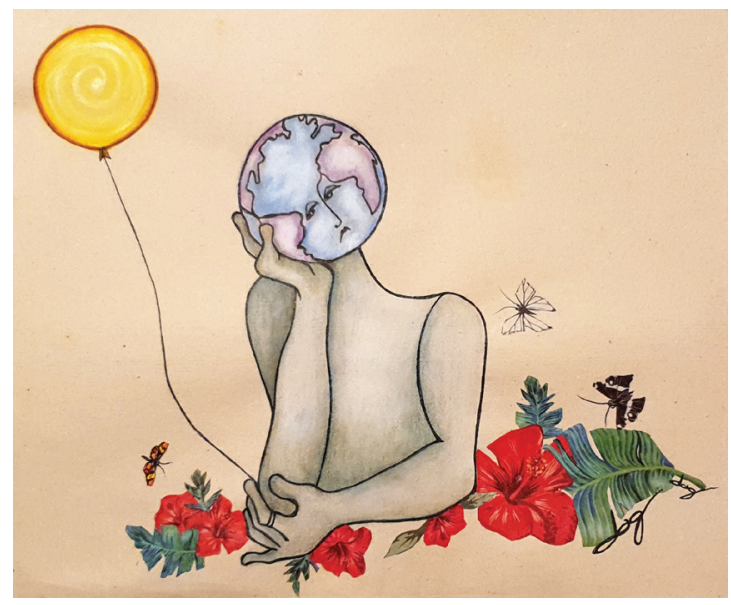

The first pandemic in the information age practically brought humanity to the same place: that of fear and uncertainty. The news of a virus that was killing people in China reached all parts of the planet along with 2020, with images of gigantic hospitals being set up overnight, forced imprisonment of thousands of people and expatriate Brazilians trying to return to the country.

Within a few weeks, the epidemic turned into a global terror with a disturbing number of deaths in Italy and confirmation of the first case in Brazil on February 26. What came after that is a script that is still under development: the death toll is on the rise and the scenario of uncertainty is getting worse.

Targeted by attacks and budget cuts since Jair Bolsonaro took office, national science has not been quiet. In a record time, Brazilian female researchers completed the genome sequence of the novel coronavirus and influenced the course of scientific investigations that followed.Withoutresourcesandfocusedoncontributing to the fight against covid-19, the name given to the disease caused by the novel coronavirus, researchers work hours uninterrupted. They also share their knowledge with the press, are active on social networks and seek international scientific collaborations.

The pandemic has highlighted, once again, the importance of science for society. After all, weapons or empty universities won't bring the cure for covid-19, but research that will find out the functioning of this virus. Vaccines or new drugs will come as a result.

Experiences in countries that suffered the outbreak before Brazil, reinforced by the World Health Organization, showed how confinement is fundamental to prevent thousands of people from becoming infected at once. Our Unified Health System would collapse as it is unable to offer intensive treatment to everyone. Despite the budget cuts suffered in the public health system in recent years, health care professionals heroically resist on the front line against the pandemic.

The challenges are enormous. It is still unclear how battered countries will emerge from this crisis. Researchers around the world are unanimous: there is no possible individual salvation. In a conversation I had with Hélio Bacha, an infectious disease specialist at the Brazilian Israeli Beneficent Society Albert Einstein, who has been researching epidemics for five decades, one of his notes particularly had an impact on me. "An epidemic will only be contained by a national policy, with an organization that all people respect. When people try to save themselves it is tragic, because they do not save themselves".

As I write this text, the Brazilian president addresses the nation on television with a message that goes in the opposite direction. As the number of covid-19 cases explodes, Bolsonaro says Brazil must return to its normal life, calls for an end to confinement and blames the press for causing panic. In other words, he contradicts science and the World Health Organization itself.

What price will Brazilians pay?

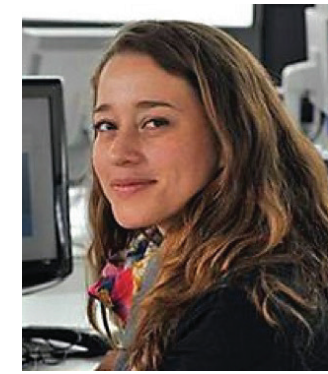

Nadia Pontes

Publisher of Science,

Technology and Environment of Brazil DW 


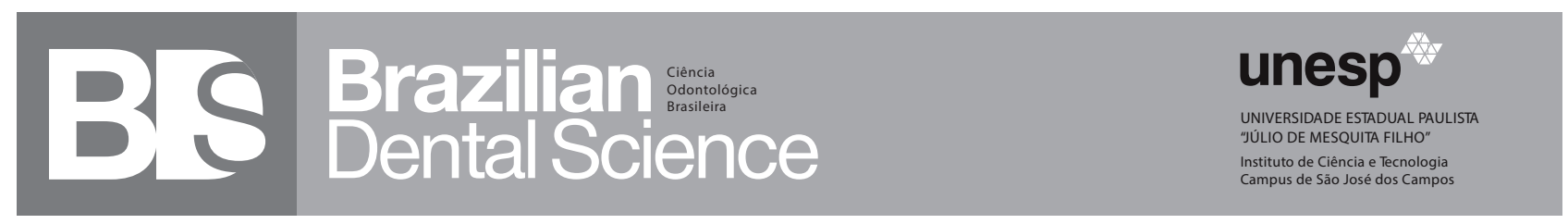

\section{PANDEMIA E CIÊNCIA}

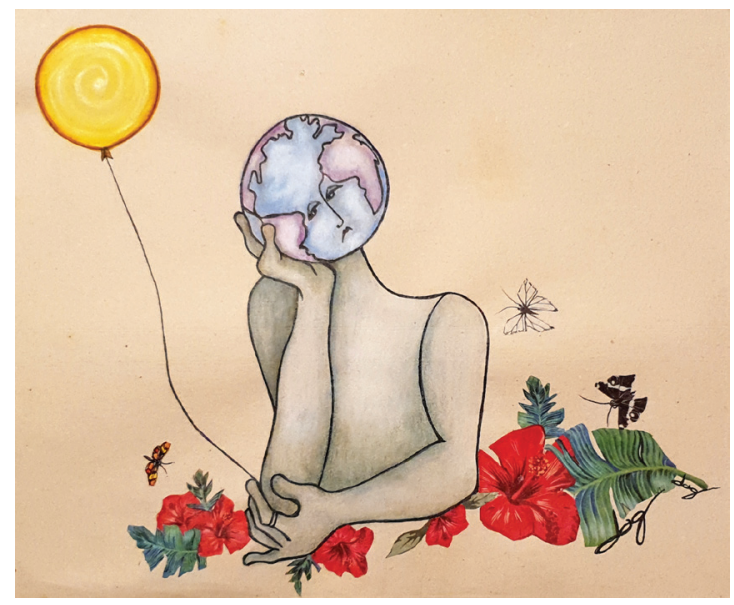

A primeira Pandemia na era da informação praticamente levou toda a humanidade a um mesmo lugar: o do medo e incerteza. As notícias de um novo vírus que fazia vítimas na China chegaram a todos os pontos do planeta juntamente com 2020, com imagens de hospitais gigantescos sendo montados da noite para o dia, reclusão forçada de milhares de pessoas e brasileiros expatriados tentando retornar ao país.

Em poucas semanas, a epidemia se transformou num terror global com número assombroso de mortes na Itália e a confirmação do primeiro caso no Brasil em 26 de fevereiro. O que veio depois disso é roteiro ainda em desenvolvimento: os doentes aumentam, as mortes ultrapassam a casa dos 45 e o cenário de incerteza se agrava.

Alvo de ataques e cortes mais severos desde que Jair Bolsonaro assumiu a presidência, a ciência nacional não se aquietou. Foram pesquisadoras brasileiras que, em tempo recorde, sequenciaram o novo coronavírus que chegou ao país e influenciaram o rumo de investigações científicas que se seguiram. Sem recursos e focados em contribuir no combate à covid-19, nome dado a doença provocada pelo novo coronavírus, pesquisadores trabalham horas a fio, compartilham conhecimento com a imprensa, fazem lives em redes sociais e buscam colaborações internacionais.

A pandemia evidenciou, mais uma vez, a importância da ciência para a sociedade. Afinal, não serão armas ou universidades fechadas que trarão a cura para a covid-19, mas pesquisas que desvendam o funcionamento desse novo coronavírus. E a partir disso virão as vacinas ou novos medicamentos.

Experiências em países que sofreram o surto antes do Brasil, reforçadas pela Organização Mundial da Saúde, mostraram como o isolamento social é fundamental para impedir que milhares de pessoas se contaminem de uma vez. O nosso Sistema Único de Saúde entraria em colapso, sem capacidade de oferecer tratamento intensivo a todos. Sucateado nos últimos anos, com diminuição de leitos e falta de contratação, os profissionais do SUS resistem heroicamente na linha de frente contra a pandemia.

Os desafios são enormes. Ainda é incerto quão combalido o Brasil sairá dessa crise. Pesquisadores que acompanham epidemias pelo mundo são unânimes: não há salvação possível individual. Numa conversa que tive com Hélio Bacha, infectologista da Sociedade Beneficente Israelita Brasileira Albert Einstein que pesquisa epidemias há cinco décadas, uma fala dele em especial me marcou. “Uma epidemia só será contida por uma política de Estado, nacional, com organização que o conjunto das pessoas respeitem. Quando as pessoas procuram se salvar sozinhas é trágico, porque elas não se salvam sozinhas".

Enquanto escrevo esse texto, o presidente do país se dirige à nação em rede nacional com uma mensagem que vai na direção contrária. Enquanto o número de casos de covid-19 explode, Bolsonaro pede que a vida "volte à normalidade", pede o fim do confinamento e culpa a imprensa de provocar pânico. Ou seja, contraria a ciência e a própria Organização Mundial da Saúde.

Que preço os brasileiros irão pagar?

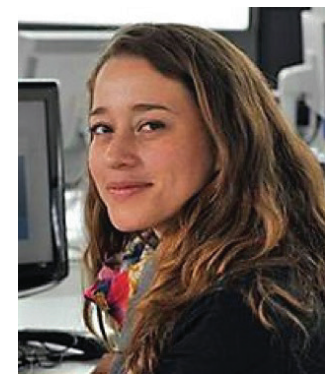

Nadia Pontes

Editora de Ciência,

Tecnologia e Meio
Ambiente do Brasil DW 